\title{
Pendampingan Pasien Isolasi Mandiri Covid-19 di UM Surabaya Melalui Psychoreligius Care
}

\author{
Radius Setiyawan ${ }^{1}$, Vella Rohmayani ${ }^{2 *}$, Dede Nasrullah ${ }^{3}$, Vika Ramadhana \\ Fitriyani $^{4}$, M Febriyanto Firman Wijaya ${ }^{5}$, Khoirul Anam ${ }^{6}$, Firman $^{7}$ \\ ${ }^{1}$ Program Studi Pendidikan Bahasa Inggris FKIP UMSurabaya \\ ${ }^{2}$ Prodi D3 Keperawatan FIK UMSurabaya \\ ${ }^{3}$ Program Studi DIV Teknologi Laboratorium Medis FIK UMSurabaya \\ ${ }^{4}$ Program Profesi Ners FIK UMSurabaya \\ ${ }^{5}$ Prodi Studi S2 Komunikasi dan Penyiaran Islam Fakultas Dakwah dan \\ Komunikasi Universitas Islam Negeri Sunan Ampel Surabaya \\ ${ }^{6}$ Prodi Studi S2 Komunikasi dan Penyiaran Islam Fakultas Dakwah dan \\ Komunikasi Universitas Islam Negeri Sunan Ampel Surabaya \\ ${ }^{7}$ Progarm Studi S2 Keperawatan FIK Universitas Indonesia
Email: radius.setiyawan@gmail.com¹, dedenasrullah@um-surabaya.ac.id², vella.yani@fik.um-surabaya.ac.id ${ }^{3}$,vikarf2@gmail.com ${ }^{4}$, mfebriyantowijaya@gmail.com ${ }^{5}$,khoirulanamelzian@gmail.com ${ }^{6}$, firman.fikumsby@gmail.com ${ }^{7}$
*Corresponding vella.yani@fik.um-surabaya.ac.id ${ }^{1}$

\begin{abstract}
ABSTRAK
Terjadinya pandemi Covid-19 gelombang 2 menimbulkan banyak masyarakat yang terkonfirmasi positif. Hal tersebut menyebabkan terjadinya over capacity di Pelayanan Kesehatan, sehingga pasien harus melakukan isolasi mandiri di rumah. Tuntutan berdiam diri di rumah dapat memicu terjadinya gangguan psikologis atau kondisi stres. Padahal kondisi stres sangat merugikan bagi tubuh, karena dapat membuat system imun menurun, serta menyebabkan gangguan kesehatan lainnya. Oleh karena itu perlu dilakukannya pendampingan psychoreligius care terhadap pasien Covid-19 yang sedang menjalani isolasi mandiri. Kegiatan pendampingan ini bertujuan untuk: 1) mengidentifikasi tingkat stres pada pasien Covid-19 yang sedang menjalani isolasi mandiri. 2) Memberikan pendampingan psikoreligius care untuk mengurangi tingkat stres pada pasien isoman. Metode pelaksanaan pertama dilakukan tahap penjaringan (pre-test), kemudian pengolahan data, implementasi pendampingan psychoreligius care dan terakhir tahap evaluasi kegiatan (post-test). Hasil pendampingan dan screening diperoleh data bahwa, 1) Pasien covid-19 mengalami kecemasan ketika sedang menjalani isolasi mandiri dengan tingkatan yang berbeda-beda. 2) Setelah dilakukan pendampingan psychoreligius care selama 14 hari terjadi penurunan tingkat kecemasan sebesar $82,86 \%$. Kegiatan pendampingan berjalan dengan baik dan masih perlu dilakukan pendampingan berlanjut mengingat ada sebesar $17,14 \%$ pasien isoman yang membutuhkan durasi waktu lebih lama untuk mengatasi kondisi kecemasan maupun stres yang terjadi pada dirinya.
\end{abstract}

Kata Kunci: Pendampingan, Isolasi Mandiri, Covid-19, Psychoreligius Care 


\title{
Assistance for Covid-19 Self-Isolation Patients at UM Surabaya with Psychoreligious Care
}

\begin{abstract}
The occurrence of the Covid-19 pandemic wave 2 caused many people who were confirmed positive. This causes overcapacity in health services, so patients must be self-isolate at home. The demand to stay at home can trigger psychological disorders or stressful conditions. Whereas stress conditions are very detrimental to the body, because it can make the immune system decrease, and it cause other health problems. Therefore, it is necessary to provide psychoreligious care assistance for Covid-19 patients who are undergoing self isolation. This mentoring activity aims to: 1) identify stress levels in Covid-19 patients who are undergoing self-isolation. 2) psychoreligious care assistance are given to reduce stress levels in isoman patients. The first implementation method is the screening stage (pre-test), then data processing, implementation of psychoreligious care assistance and finally the activity evaluation stage (post-test). The results of mentoring and screening obtained data that, 1) Covid-19 patients experienced anxiety while undergoing independent isolation with different levels. 2) After 14 days of psychoreligious care assistance, there was a decrease in anxiety levels of $82.86 \%$. Mentoring activities are going well and there is still a need for continued assistance considering there are $17.14 \%$ of isoman patients who need a longer duration of time to deal with anxiety and stress conditions that occur to them.
\end{abstract}

Keywords: Assistance, Self-Isolation, Covid-19, Psychoreligious Care

\section{PENDAHULUAN}

Pandemi Covid-19 belum ada tanda-tanda berakhir, bahkan penyebarannya semakin meningkat. Pada gelombang kedua pandemi Covid-19 di Indonesia terjadi kenaikan angka terkonfirmasi positif pada awal bulan Januari-Februari 2021, hingga puncaknya terjadi pada bulan Juni 2021. Menurut Wiku Adisasmito dikutip dari situs Satgas Covid-19, Rabu (30/6) bahwa Indonesia saat ini berada dalam posisi second wave atau gelombang kedua kenaikan kasus Covid-19.

Melonjaknya kembali kasus Covid-19 mengakibatkan daya tampung rumah sakit rujukan darurat mengalami over capacity. Sebagian rumah sakit harus menolak merawat pasien, dan membuat penderita Covid-19 terpaksa harus menjalani isolasi mandiri (isoman). Situasi tersebut mendorong orang untuk menghadapi situasi yang menyedihkan dan tidak terduga (Martínez-Rodríguez et al., 2021).
Ketidakpastian dan jarak sosial merubah perilaku orang, berdampak pada perasaan mereka, kebiasaan sehari-hari, dan hubungan sosial, yang merupakan elemen inti dalam kesejahteraan manusia. Secara khusus, pembatasan karena isolasi mandiri meningkatkan perasaan kesepian dan kecemasan bahkan dapat menimbulkan stres (Boursier et al., 2020).

Kondisi semakin turunnya kesehatan mental selama menjalani isolasi mandiri dapat disebabkan oleh beberapa faktor yaitu, angka kematian akibat Covid-19 yang terus bertambah, banyaknya berita hoax yang beredar di kanal media, kesulitan atau penurunan ekonomi, serta lamanya durasi isolasi mandiri (Lei et al., 2020). Peningkatan yang signifikan dalam gejala stres pascatrauma pada isoman selama lebih dari 10 hari selama isolasi mandiri dibandingkan dengan isoman selama $<10$ hari (Nkire et al., 2021). 
Secara psikologis dalam kondisi perubahan yang terjadi secara cepat seperti saat ini, yaitu perubahan kebiasaan, perubahan perilaku, perubahan cara belajar dan bekerja, dapat menyebabkan munculnya emosi-emosi atau perasaan negative. Menurut Damayanti (2020) bahwa disetiap adanya perubahan pada kehidupan manusia maka akan mengarahkan mereka agar dapat beradaptasi dengan adanya perubahan tersebut, sehingga kondisi itu terkadang memicu stres pada manusia. dengan demikian perlu adanya sentuhan kerohanian dalam diri seseorang dalam hal keagamaan untuk mengurangi stres.

Ada beberapa penelitian yang melakukan penanganan masalah kecemasan/ stres dengan pendekatan spiritual. Menurut subandi et al, (2013) bentuk psikoterapi yang dimaskud yaitu psychoreligius care. Terapi tersebut melalui pendekatan aspek keagamaan yang bertujuan untuk meningkatkan koping dan mengatasi masalah kecemasan individu.

Kebutuhan keagamaan memang memiliki peranan vital dalam kehidupan manusia, masuk dalam tatanan kehidupan secara pribadi dan tatanan sosial kemasyarakatan. Dengan demikian agama mengatur pemeluknya untuk berada dalam jalan yang telah ditentukan dan di atur. Keyakinan terhadap agama memberikan efek bagi setiap individu karena agama mampu menggairahkan semangat hidup seseorang, meluaskan kepribadian, memperbarui daya hidup, serta mampu memberikan makna dan kemuliaan baru pada halhal yang biasa dalam kehidupan. Oleh karena perlu dilakukannya pendampingan psychoreligius care terhadap pasien covid-19 yang sedang menjalani isolasi mandiri. Melalui kegiatan pendampingan peneliti memiliki tujuan untuk: 1) mengidentifikasi tingkat stres pada pasien covid-19 yang sedang menjalani isolasi mandiri. 2) Memberikan pendampingan psikoreligius care untuk mengurangi tingkat stres pasien isoman.

\section{METODE PENELITIAN}

Tempat Dan Waktu Pelaksanaan

Kegiatan pengabdian berupa penguatan mental keagamaan (psychoreligius care) pasien Covid19 yang sedang menjalani isolasi mandiri dirumah. Kegiatan pendampingan ini bekerjasama dengan Fakultas Ilmu Kesehatan dan Fakulas Agama Islam (FAI) Universitas Muhammadiyah Surabaya. Kegiatan pendampingan dilakukan pada bulan Juni 2021.

\section{Sasaran}

Sasaran pada pendampingan psikoreligius care adalah dosen, tenaga kependidikan (TKP), mahasiswa UM Surabaya, serta warga Muhammadiyah yang terkonfirmasi positif dan sedang melakukan isolasi mandiri di rumah. Secara psikologis mereka perlu diberikan penguatan dan pembinaan bagaimana menghadapi dan melaksanakan isolasi mandiri dengan baik dan benar.

Prosedur pelaksanaan

Adapun Prosedur pelaksanaan kegiatan pendampingan psychoreligius care dilakukan melalui tahapan berikut ini, yaitu:

1. Tahap persiapan atau pra pelaksanaan, meliputi:

a. Tahap Penjaringan, Mengisi Form yang sudah disediakan 
meliputi Identitas diri, dan

screening kondisi psikologis terdiri dari kuesioner kecemasan dan stres (Pretest).

b. Tahap pengolahan data, setelah data google form diterima, selanjutnya dilakukan penilaian mengenai screening kondisi psikologis peserta oleh tim dari Fakultas Ilmu Kesehatan.

2. Tahap pelaksanaan, setelah diketahui score dan tingkat psikologis terutama kecemasan maka perlu dilakukan psikoreligius care. Pembinaan melalui Zoom Meeting setiap hari selama isoman pada jam 09.3010.30 WIB, dengan mentor dosen yang berasal dari Fakultas Agama Islam dan Fakultas Ilmu Kesehatan. Pembinaan psychoreligius care berupa tausiah, motivasi dan doa bersama. Pembinan dilaksanakan dengan metode presentasi, tanya jawab, game yang tentu dapat menyenangkan dan menghibur peserta Isoman.

3. Tahap Evaluasi, dalam tahap ini dibagi dilakukan 2 kali post-test. post-test pertama dilakukan pada hari ke 7 dan post-test kedua dilakukan pada hari ke 14. Proses eveluasi atau pemberian post-test dilakukan dengan pengisian form screening kecemasan seperti halnya saat tahap awal. Kemudian form screening yang telah di isi di nilai kembali untuk mengetahui tingkat kecemasan peserta isoman.

Adapun jadwal pelaksanaan kegiatan psychoreligius care untuk pasien Isoman Covid-19 adalah sebagaimana berikut ini:

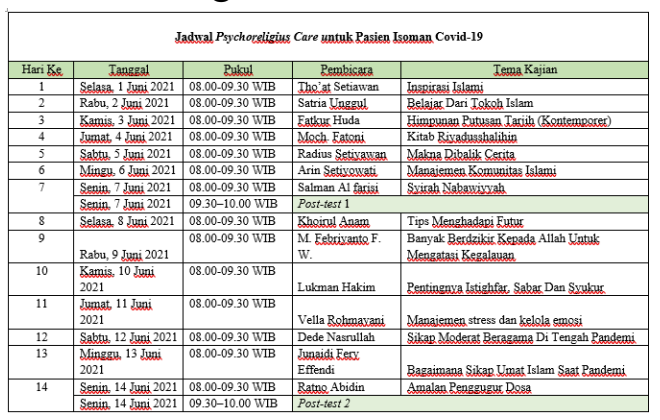

Gambar 1: Jadwal Kegiatan psychoreligius care

\section{HASIL DAN PEMBAHASAN}

Adapun data persentase peserta yang mengikuti kegiatan pendampingan pasien isolasi mandiri dalam bentuk pscycoreligius care adalah sebagaimana berikut ini:

Tabel 1. Data Umum Karakteritik Peserta

\begin{tabular}{lcc}
\hline Karakteristk & \multicolumn{2}{c}{ Responden } \\
\hline & $\begin{array}{c}\text { Frequ } \\
\text { ency }\end{array}$ & $\begin{array}{c}\text { Presentase } \\
(\%)\end{array}$ \\
\hline Status & & \\
\hline Mahasiswa & 15 & $42,86 \%$ \\
\hline Dosen & 6 & $17,14 \%$ \\
\hline TKP & 4 & $11,43 \%$ \\
\hline $\begin{array}{l}\text { Warga } \\
\text { Muhammdiy } \\
\text { ah }\end{array}$ & 10 & $28,57 \%$ \\
\hline Total & 35 & $100 \%$ \\
\hline $\begin{array}{l}\text { Jenis } \\
\text { Kelamin }\end{array}$ & & \\
\hline Perempuan & 19 & $54,29 \%$ \\
\hline Laki-laki & 16 & $45,71 \%$ \\
\hline Total & 35 & $100 \%$ \\
\hline
\end{tabular}


Berdasarkan tabel di atas dapat diketahui bahwa jumlah peserta yang mengikuti kegiatan pscycoreligius care adalah sebesar 35 yang terdiri dari 15 mahasiswa, 6 dosen, 4 TKP dan 10 warga muhammadiyah. Dimana responden terbanyak berjenis kelamin perempuan.

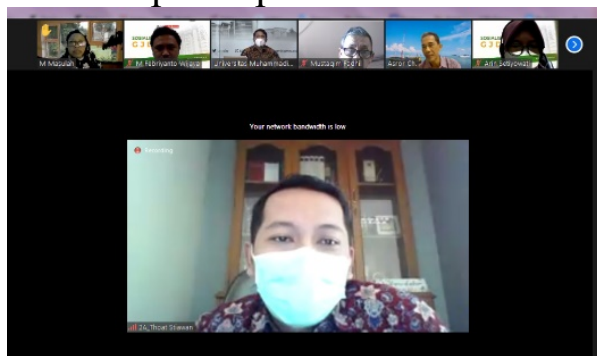

Gambar 2: Dokumentasi

pendampingan hari ke 1 oleh bapak

Tho'at Setiawan (Dosen FAI)

\section{Data Hasil Pre-Test dan Post-Test}

Berikut ini merupakan data hasil pre-test dan post-tes peserta kegiatan pscycoreligius care.

Tabel 2. Data Khusus Tingkat Kecemasan

\begin{tabular}{lccc}
\hline \multicolumn{1}{c}{$\begin{array}{c}\text { Kategori } \\
\text { Tingkat }\end{array}$} & \multicolumn{3}{c}{ Responden } \\
\cline { 2 - 4 } Kecemasan & $\begin{array}{c}\text { Pre } \\
-\end{array}$ & $\begin{array}{c}\text { Post }- \\
\text { test } 1\end{array}$ & $\begin{array}{c}\text { Post }- \\
\text { test } 2\end{array}$ \\
& test & & \\
\hline $\begin{array}{l}\text { Tidak ada } \\
\text { Kecemasan }\end{array}$ & & 5 & 29 \\
\hline $\begin{array}{l}\text { Kecemasan } \\
\text { Ringan }\end{array}$ & 10 & 24 & 6 \\
\hline $\begin{array}{l}\text { Kecemasan } \\
\text { Sedang }\end{array}$ & 17 & 5 & \\
\hline $\begin{array}{l}\text { Kecemasan } \\
\text { Berat }\end{array}$ & 5 & 1 & \\
\hline Panik/ Stres & 3 & & \\
\hline Total & 35 & 35 & 35 \\
\hline
\end{tabular}

Berdasarkan hasil data pre-test dari 35 peserta yang menjelani isolasi mandiri menunjukkan bahwa semua peserta mengalami kecemasan atau persentase kecemasan sebesar $100 \%$. Dimana tingkat kecemasan setiap peserta berbeda-beda, yaitu kecemasan ringan sebesar 28,57\%, kecemasan sedang sebesar 48,57\%, kecemasan berat sebesar 14,29\% dan kondisi panik atau stres sebesar $8,71 \%$.

Diketahui bahwa kondisi stres dapat merugikan bagi tubuh, karena menyebabkan terjadinya penurunan system imun hingga menyebabkan gangguan kesehatan yang serius. Menurut Handayani menyebutkan bahwa stres merupakan salah satu gangguan psikologis yang banyak terjadi selama masa pandemi Covid-19. Kondisi tress dapat di rasakan oleh masyarakat umum, terlebih pada pasien terkonfirmasi positif Covid-19 yang menjalani isolasi mandiri.

Gangguan psikologis atau kondisi stres akan menimbulkan dampak yang lebih luas dan lebih lama dibandingkan dengan terjadinya cedera fisik pada tubuh. Adapun reaksi stres mencakup rasa cemas, cepat marah, sulit tidur, penurunan imun tubuh, penurunan produktivitas, bahkan pada kondisi tertentu dapat menyebabkan masalah kejiwaan yang lebih parah.

kondisi stres yang tidak dapat dikendalikan, akan memicu terjadinya peningkatan produksi hormon korsitol secara berlebihan. Ketidakseimbangan kadar hormon kortisol dapat menyebabkan berbagai gangguan kesehatan pada tubuh. Diketahui bahwa peningkatan kadar hormon kortisol dalam jangka waktu 
yang lama dapat menyebabkan ketidakseimbangan fungsi fisiologis tubuh, seperti gangguan kadar gula darah, gangguan kesehatan reproduksi, gangguan sistem pencernaan, gangguan sistem imun tubuh, dan lain seterusnya.

Berdasarkan penelitian yang dilakukan oleh Fancourt et al., (2021) menyatakan bahwa self isolation dapat menimbulkan kecemasan bahkan depresi. Penelitian lain yang dilakukan oleh Gaeta \& Brydges, (2020) menjelaskan bahwa ada hubungan signifikan karantina/ isolasi mandiri terhadap kecemasan dan kesepian pasien covid-19.

Kotwal et al., (2021) dalam penelitiannya menyatakan durasi self isolation yang lebih lama dikaitkan dengan kesehatan mental. Durasi lebih dari 10 hari menunjukkan secara signifikan lebih tinggi memunculkan gejala stres pasca trauma dibandingkan dengan durasi yang kurang dari 10 hari. Gangguan kesehaan mental sendiri bisa berupa murung, kurang bersemangat, cemas, gangguan tidur dan rindu keluar rumah bertemu orang lain, bahkan kehilangan motivasi kerja. Selain tertekan karena wabah yang tak kunjung reda (Brooks et al., 2020).

Dari tabel 2 dapat dilihat terjadinya perubahan yang cukup signifikan antara hasil pre-test, posttest 1 dan post-test 2. Dimana terjadi penurunan tingkat kecemasan setelah dilakukan pendampingan pscycoreligius care. Pada post-test 1 terjadi penurunan kecemasan dari awalnya terdapat 35 orang yang mengalami stres menjadi 30 orang atau terjadi penurunan persentase kecemasan pada pasien isoman sebesar 14,29\%. Kemudian pada post-test 2 terjadi penurunan kecemasan dari 30 orang menjadi 6 orang yang masih mengalami kecemasan atau terjadi penurunan persentase kecemasan pada pasien isoman sebesar $80 \%$. Sehingga persentase penurunan kecemasan pada pasien isoman Covid-19 secara keseluruhan dari 35 orang yang mengalami pasien setelah dilakukan pendampingan pscycoreligius care selama 14 hari, hanya tinggal 6 orang pasien isoman yang masih mengalami kecemasan atau terjadi penurunan persentase sebesar $82,86 \%$. Adapun $17,14 \%$ pasien yang masih mengalami kecemasan berada pada tingkat kecemasan ringan.

Terapi tersebut yang berupa siraman rohani, materi Kesehatan, motivasi dan doa bersama dapat digunakan sebagai koping yang dapat meningkatkan semangat dan membangkitkan ketahanan tubuh seara alami. Selain itu, tingkat religiusitas yang tinggi dapat meningkatkan mood dan menyehatkan diri individu (Ahmad Asyroful, 2017).

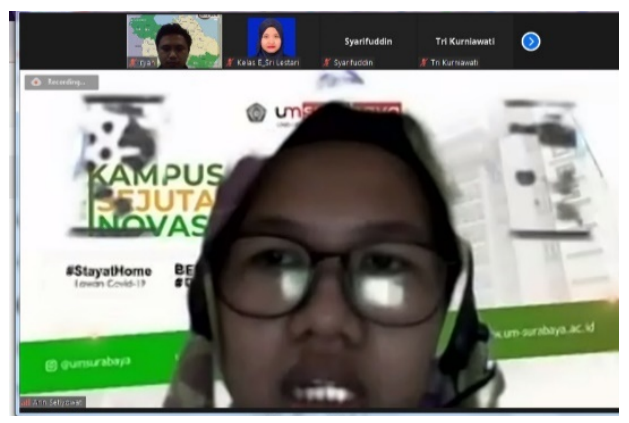


Gambar 3: Dokumentasi

pendampingan hari ke 6 oleh ibu

Arin Setyowati (Dosen FAI)

Psikoreligius (keagamaan) secara Islami, yaitu suatu perlakuan dan pengobatan yang ditujukan kepada penyembuhan suatu penyakit mental, kepada setiap individu, dengan kekuatan batin atau ruhani, yang berupa ritual keagamaan bukan pengobatan dengan obat-obatan, dengan tujuan untuk memperkuat iman seseorang.

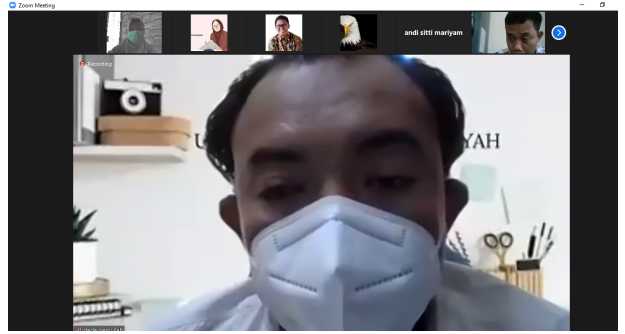

Gambar 4: Dokumentasi

pendampingan hari ke 12 oleh bapak

Dede Nasrullah (Dosen FIK)

\section{SIMPULAN}

Kegiatan pembinaan berjalan dengan baik dan lancar. Berdasarkan hasil pembinaan menunjukan bahwa isolasi mandiri dapat menimbulkan penurunan Kesehatan mental baik kecemasan maupun stres . Pemberian pembinaan melalui psychoreligius care selama masa isolasi mandiri terbukti efektif menurunkan tingkat kecemasan peserta isolasi mandiri.

\section{UCAPAN TERIMA KASIH}

Disampaikan terima kasih kepada berbagai pihak yang membantu kelancaran kegiatan pengabdian ini, yaitu kepada: a. Fakultas Ilmu Kesehatan yang telah membantu dalam proses penilaian hasil screening untuk

b. Fakultas Agama Islam yang telah membantu pelaksaan pendampingan psycoreligius care

c. Seluruh peserta pendampingan yakni dosen, TKP, mahasiswa UM Surabaya, serta warga Muhammadiyah terkonfirmasi Covid-19 yang sedang menjalani isolasi mandiri di rumah.

\section{DAFTAR PUSTAKA}

Asyroful, Ahmad. (2017). Pengaruh Psycholegius care: Terhadap Penurunan Kecemasan. Universitas Airlangga

Boursier, V., Gioia, F., Musetti, A., \& Schimmenti, A. (2020). Facing Loneliness and Anxiety During the COVID-19 Isolation: The Role of Excessive Social Media Use in a Sample of Italian Adults. Frontiers in Psychiatry, 11(December), 1-10. https://doi.org/10.3389/fpsyt.20 20.586222

Brooks, S. K., Webster, R. K., Smith, L. E., Woodland, L., Wessely, S., Greenberg, N., \& Rubin, G. J. (2020). The psychological impact of quarantine and how to reduce it: rapid review of the evidence. The Lancet, 395(10227), 912-920. https://doi.org/10.1016/S01406736(20)30460-8

Collaborative, T. C.-. (2021). Perceived Stres of Quarantine and Isolation During COVID-19 Pandemic: A Global Survey. Frontiers in Psychiatry, 
12(May), $1-10$. https://doi.org/10.3389/fpsyt.20 21.656664

Fancourt, D., Steptoe, A., \& Bu, F. (2021). Trajectories of anxiety and depressive symptoms during enforced isolation due to COVID-19 in England: a longitudinal observational study. The Lancet Psychiatry, 8(2), 141-149.

https://doi.org/10.1016/S22150366(20)30482-X

Gaeta, L., \& Brydges, C. R. (2020). Coronavirus-Related Anxiety, Social Isolation, and Loneliness in Older Adults in Northern California during the Stay-atHome Order. Journal of Aging and Social Policy, 00(00), 1-12. https://doi.org/10.1080/0895942 0.2020 .1824541

Handayani, R. T. (2020). Kondisi dan strategi penanganan kecemasan pada tenaga kesehatan saat pandemi Covid-19. Jurnal Ilmu Keperawatan Jiwa, 3(3), 367376.

Kotwal, A. A., Holt-Lunstad, J., Newmark, R. L., Cenzer, I., Smith, A. K., Covinsky, K. E., Escueta, D. P., Lee, J. M., \& Perissinotto, C. M. (2021). Social Isolation and Loneliness Among San Francisco Bay Area Older Adults During the COVID-19 Shelter-in-Place Orders. Journal of the American Geriatrics Society, 69(1), 20-29. https://doi.org/10.1111/jgs.1686 5

Lei, L., Huang, X., Zhang, S., Yang, J., Yang, L., \& Xu, M. (2020). Comparison of Prevalence and Associated Factors of Anxiety and Depression among People Affected by versus People
Unaffected by Quarantine during the COVID-19 Epidemic in Southwestern China. Medical Science Monitor, 26, 1-12. https://doi.org/10.12659/MSM.9 24609

Martínez-Rodríguez, T. Y., BernalGómez, S. J., Mora, A., Hun, N., Reyes-Castillo, Z., ValdésMiramontes, E. H., \& EspinozaGallardo, A. C. (2021). Dysfunctional patterns of food intake by anxiety during isolation by COVID-19 in Chile, Colombia and Mexico. International Journal of Psychological Research, 14(1), 48-54.

https://doi.org/10.21500/201120 84.4721

Nkire, N., Mrklas, K., Hrabok, M., Gusnowski, A., Vuong, W., Surood, S., Abba-Aji, A., Urichuk, L., Cao, B., Greenshaw, A. J., \& Agyapong, V. I. O. (2021). COVID-19 Pandemic: Demographic Predictors of Self-Isolation or Self-Quarantine and Impact of Isolation and Quarantine on Perceived Stres , Anxiety, and Depression. Frontiers in Psychiatry, 12(February). https://doi.org/10.3389/fpsyt.20 21.553468

Subandi, Lestari, R and Suprianto T. (2013). Pengaruh Terapi Psikoreligius Terhadap Penurunan Tingkat Ansietas Pada Lansia di UPT Pelayanan Sosial Lanjut USia Sejahteta Pandaan Pasuruan.BIMIKI.Volume 2.pp.22-33 
Radius Setiyawan, Vella Rohmayani, Dede Nasrullah, Vika Ramadhana Fitriyani, M Febriyanto Firman Wijaya, Khoirul Anam, Firman/Aksiologiya: Jurnal Pengabdian Kepada Masyarakat. Vol. 5, No. 4, November 2021 Hal 466 - 474 